\title{
Mobile Phone Adoption in Agri-food sector: Are Farmers in Sub-Saharan Africa Connected?
}

\author{
Ronald Kabbiria,b, Manoj Dorac, Vikas Kumard, Gabriel Elepu ${ }^{\mathrm{e}}$ and Xavier Gellynck ${ }^{\mathrm{a}}$ \\ ${ }^{a}$ Department of Agricultural Economics, Ghent University, Belgium \\ ${ }^{b}$ School of Agriculture and Environmental Sciences, Mountains of the Moon University, \\ Uganda \\ ${ }^{c}$ Brunel Business School, Brunel University, London, UK \\ ${ }^{d}$ Bristol Business School, University of the West of England, Bristol, UK \\ ${ }^{e}$ Department of Agribusiness and Natural Resource Economics, Makerere University, Uganda
}

\begin{abstract}
In recent years user acceptance of a new technology has become of much interest. One of the most outstanding global problems facing Africa is the digital divide. However, the use and adoption of mobile phones is reducing the digital divide in Africa. In view of the role that mobile phones play in bridging the digital divide in Africa, this study extends the applicability of the technology acceptance model (TAM), without altering its parsimony and information technology focus, in mobile phone adoption. This paper extends the TAM model by adding two new constructs, perceived advantage and socioeconomic characteristics. Consequently, the extended TAM was applied to adoption of mobile phones in farming communities in Sub-Saharan Africa. The study relies on a sample from 300 dairy farmers in Uganda which was analysed using structural equation modelling. Theoretically, it contributes to the limited literature on mobile phone adoption in agri-food sector in Sub-Saharan Africa and provides empirical evidence from Ugandan farmers. The research contributes to promoting mobile phone usage in farming communities beyond just normal communication. The research also has a strong practical implication for farmers as well as other stakeholders from the agri-food sector.
\end{abstract}

Keywords: Dairy Value Chain; Extended Technology Adoption Model; Smartphone Use; Structural Equation Modelling; Uganda 


\section{Introduction}

Advancement in information and communication technologies (ICT) has facilitated doing business and economic development in the world. The impact of this technological advancement, to some extent, is not equitable. Although much of the impact of this technological advancement is in American and European countries, its rate of spread is fairly low in many African and Asian countries. This slow rate of spread of these impacts can be attributed to digital divide (Fuchs and Horak, 2008, James, 2009a).

Digital divide refers to the gap between demographics and regions that have access to modern ICT and those that do not or have restricted access (Rouse, 2014). These ICTs include mobile phones, television, personal computers and the internet. Among these, the mobile phone has become popular in recent years; its use and adoption is reducing the digital divide in Africa (Costantini and Liberati, 2014). The mobile phone is changing the face of Africa. Compared to other ICTs, the mobile phone is less demanding in terms of affordability, user capabilities, and infrastructure requirements (James, 2009a, Osabutey and Jin, 2016). Doing business in Africa has improved since the introduction of mobile phones. Because of the mobile phone, Africa has been able to develop by skipping landline and associated infrastructural development costs (Amankwah-Amoah, 2016, James, 2009b). It is in Africa where the mobile phone overtook the number of fixed line telephones (James, 2009b, Galang, 2012). Consequently, Africa is connected and opportunities for doing business in Africa have increased (Amankwah-Amoah, 2015).

User acceptance of a new technology has become of much interest in research recently. The approach in studying this concept has comprised testing key factors of adoption, behavioural intention and usage of a technology by individual users (Park and del Pobil, 2013). Several theories have been put forward to explain intention to use or adopt a technology. The most popular one with support from literature (Chuttur, 2009, Luarn and Lin, 2005) is the technology acceptance model (TAM).

The TAM is very flexible and can accommodate many variables. It has thus become popular in information technology acceptance and adoption literature. In this model, intention to use a technology determines its adoption. Subsequently, perceived ease of use and perceived usefulness determines intention to use the technology (Chuttur, 2009, Wu and Wang, 2005, Kim et al., 2008). Some of its strengths are parsimony, validity and reliability of its instruments. One major limitation of the model is the assumption of non-existence barriers which may prevent an individual from using a given technology (Luarn and Lin, 2005, Chuttur, 2009). Circumstances such as time constraint, lack of money and expertise may limit an individual from using a technology (Mathieson et al., 2001, Malhotra and Galletta, 1999).

Mobile phones are not very well spread among the farming communities in the agri-food sector in SubSaharan Africa. The technology, however, is popular amongst traders. Unlike traders who use mobile phones for searching for price information in different agri-food markets, the majority of farmers use them for normal communication, i.e., to keep in touch with family and friends. Research has shown that farmers in Sub-Saharan Africa hardly use mobile phones to keep themselves updated with prices of different produce/commodities in different markets (Aker, 2009, Aker and Mbiti, 2010, Overå, 2006, Muto and Yamano, 2009). With the popularity of the mobile phone in Sub-Saharan Africa, all stakeholders in the value chain can be connected. In the current situation, however, farmers do not seem to be well connected with other value chain actors. Farmers, being at the upstream, are liable to exploitation from other chain actors, especially the middlemen. They are ignorant about what takes place in markets. Consequently, they accept any price that the middlemen offer them for their produce/commodity. If farmers, like middlemen, can keep themselves connected with different markets, they will be safe from exploitation. Further, research has indicated that mobile phones, if well 
utilised, can improve the influence of Sub-Saharan farmers in the value chain (Faida, 2006). They can be transformed into chain partners.

Previous research indicates that farmers in Sub-Saharan (Aker and Mbiti, 2010) may choose not to use a new technology (like a mobile phone) due to lack of required knowledge, skills or abilities. Besides, farmers may also fail to use a technology if they are unaware of its advantages (Luarn and Lin, 2005). As a result, farmers are likely to miss the full potential of this new technology, which has the potential to improve farmers' welfare. A person may feel that a mobile phone is useful and easy to use, however, he/she may not maximally use it until he/she realises some perceived advantages associated with it. These advantages include making timely decisions and getting updates on market prices. Realising the benefits that technology can bring to farmer's welfare it is therefore essential to understand how people accept new technologies. The original TAM model doesn't consider perceived advantage and socio-economic characteristic aspects. This study therefore aims to address this gap by extending the TAM by adding two new constructs, perceived advantage and socio-economic characteristics (Bayard and Jolly, 2007, Mittal et al., 2010). In addition, the study contributes to scant literature on mobile phone adoption in Uganda and Sub-Saharan Africa at large. Moreover, this study also provides empirical evidence from Ugandan farmers. Practically, the study will enhance an understanding of an individual's behaviour to adopt and fully utilise mobile phones.

Next section discusses the theoretical background of this study. A brief overview of the mobile phone adoption in Sub-Saharan Africa has been provided and TAM model has been discussed in detail. Section 3 discusses the research model and proposes a number of hypotheses that were empirically tested. Research design and method is presented in section 4 . Section 5 presents the result of this study. Discussion of the findings is provided in section 6 whereas section 7 concludes this study and also highlights some limitations and areas for future research.

\section{Theoretical background}

A survey of literature by Feder et al. (1985) on factors underlying adoption decisions in Africa forms a basis for most studies on adoption. Extensive work has been done on adoption of technologies in Africa since it provides a basis for increased production and income (Croppenstedt et al., 2003, Feder et al., 1985, Kassie et al., 2013). However, much of this research focuses on adoption of improved crops and new methods of cultivation (Khonje et al., 2015, Kassie et al., 2013, Kassie et al., 2015, Fisher et al., 2015). In addition, most of these studies are dichotomous in nature (i.e. compare adoption to nonadoption) (Feder et al., 1985). One major weakness with most of these studies is the fact that they ignore the role of ICT in adoption (Doss, 2006, Feder et al., 1985). In the context of Africa, in order to realise increased production and income resulting from adoption of technologies, there is need to refocus studies on adoption (James, 2009b, Doss, 2006, Ndiritu et al., 2014). The mobile phone technology, which is spreading tremendously in Africa, plays a vital role in facilitating realisation of benefits from adoption of technologies.

\subsection{Mobile phone adoption in the world, Sub-Saharan Africa and Uganda}

Mobile phones have become a major form of communication in the world. Mobile phone networks play the same role that fixed-line phone networks did in facilitating growth in Europe and North America in the 20th century. The expansion of the mobile phone networks has been tremendous in the recent past. In 2015, there were 4.7 billion unique mobile subscribers globally, equivalent to $63 \%$ of the world's population (GSMA, 2016, Katz, 2008). GSMA (2016) further projects that by 2020, almost three-quarters of the global population will have a mobile subscription, with around 1 billion new 
subscribers added over the period. However, developed markets are growing more slowly as penetration rates approach levels close to saturation. Adoption rates reached $65 \%$ of the connection base in the developed world at the end of 2015, ranging from 59\% in Europe to 74\% in North America (GSMA, 2016, Aker and Mbiti, 2010, Katz, 2008). Smartphone adoption is accelerating across the developing world; smartphone connections reached $40 \%$ of the total connections base by the end of 2015 (up from 5\% in 2010), largely due to growth in Asia Pacific and Latin America. The number of smartphone connections will increase by 2.6 billion by 2020 , with more than $90 \%$ of that growth from developing regions.

In Sub-Saharan Africa, the mobile industry continues to scale rapidly reaching 367 million subscribers by the end of 2015 (GSM, 2015, Aker and Ksoll, 2016, GSMA, 2016, Katz, 2008). Migration to higher speed networks and smartphones continues apace, with mobile broadband connections set to increase from just over $20 \%$ of the connection base today to almost $60 \%$ by the end of the decade (Albiman et al., 2016, Asongu and Le Roux, 2016). Falling device prices are encouraging the rapid adoption of smartphones, with the region set to add more than 400 million new smartphone connections by 2020 , by which time the smartphone installed base will total over half a billion (GSMA, 2016, Aker, 2010).

The mobile industry remains a key driver of economic growth and employment across the region, making an important contribution given the population growth and high unemployment levels (James and Versteeg, 2007). In 2014, the broader mobile ecosystem generated 5.7\% of GDP in Sub-Saharan Africa, a contribution of just over $\$ 100$ billion in economic value (Aker, 2010, James and Versteeg, 2007). Migration to mobile broadband and the growth of new services will see this figure increase to $8.2 \%$ of GDP by 2020, reflecting how increased access to mobile services generates regional growth and development (Asongu and Le Roux, 2016, Albiman et al., 2016).

Mobile phone technology plays a central role in addressing a range of socio-economic developmental challenges across the region, particularly digital and financial inclusion (James and Versteeg, 2007, Abraham, 2006, Albiman et al., 2016). Greater digital inclusion will drive economic and infrastructure development, increasing productivity and employment across the economy, and will improve access to vital services such as agriculture, education and healthcare.

Deichmann et al. (2016) reviewed literature on how technology impacts rural sector in developing countries and how digital technologies overcome information problems that hinder market access for small-scale farmers. The major challenge the authors pointed out is that the extension activities through mobile technologies have not scaled up to the extent expected. Similarly, Jain et al. (2015) conducted a survey among farmers in India to understand needs and challenges of use of internet and mobile phones in agriculture. Their results show that mobile technologies need to consider localisation and integrating native language of farmers to be more successful.

Sub-Saharan Africa continues to lead the world in the adoption of mobile money services. At the end of 2014, more than one-fifth of mobile connections in the region were linked to a mobile money account, with more registered mobile money accounts than bank accounts in a number of countries (GSM, 2015, Albiman et al., 2016, Asongu and Le Roux, 2016, Asongu and Nwachukwu, 2016).

Mobile phones in Sub-Saharan Africa have significantly improved people's access to information, especially for the rural poor who were never connected to landline phones before. They have also reduced certain transaction costs, hence improving functioning of markets in various sectors, including agriculture, health, education, financial services, etc. (Aker, 2010). Further, Batchelor et al. (2014) carried out a qualitative study by conducting 50 in-depth consultations with experts in Agriculture and ICT. Their study claims, mobile phones accelerate the uptake of sustainable agriculture in Africa. 
However, the study recommended a strong co-operative and focused effort across different stakeholders' groups, such as local actors, private sector, expert institutions, and national governments. Chavula (2014) carried out an interesting study using panel data over ten years to find out if the proliferation of ICT in Africa has had any impact on agricultural production. The results were striking. The author noted that mobile phones have an insignificant impact on production while telephone main lines play a significant role.

ICT is also very important to Uganda, like any other Sub-Saharan African country. In Uganda, the number of mobile phone subscribers increased from 776,200 to over 8.5 million from 2004 to 2008 (GSM, 2015, GSMA, 2016). At least 52.3 per cent of Ugandans have access to mobile phones, which translates into more than 19.5 million Ugandans (out of 35 million) connected to different mobile telecommunications networks (Martin and Abbott, 2010, Muto and Yamano, 2009, Sekabira and Qaim, 2017). Mobile phone accessibility in Uganda has been on a trajectory growth, increasing to 20.7 per cent in 2008 and 46.7 per cent before growing to 52.3 per cent in 2014. This shows that Uganda is on the path to maximum tele-density penetration with an annual growth of about 20 per cent. In addition to calling and SME services, mobile money has also become a prominent service for mobile phone users in Uganda.

The agricultural sector plays a significant role in Uganda's economy as it is the main source of livelihood and employment for over 60 percent of the population. This sector also contributes over 70 percent of Uganda's export earnings and provides the bulk of the raw materials for most of the industries that are predominantly agro-based. In Uganda agricultural output primarily comes from about 3 million smallholder subsistence farmers (FAO, 2003, UBOS, 2016). Mobile phone use by farmers in the Ugandan agri-food sector however still remains unpopular. Compared to other Sub-Saharan African countries, perhaps Uganda lags behind in terms of mobile phone use in agriculture (GSM, 2015, Aker, 2010). This forms a good basis for the Ugandan case to be used in this study of mobile phone adoption in Sub-Saharan Africa. Majority of studies on mobile phones in Africa have been conducted elsewhere, i.e. Ethiopia, Niger, Nigeria and Kenya (Aker and Fafchamps, 2015, Aker and Ksoll, 2016, Asongu and Le Roux, 2016, Ouma et al., 2017, Kibere, 2016).

Recently, there has been a propagation of mobile phone-based applications and services in the agrifood sector, which provides information on market prices, weather, transport and agricultural techniques via voice, short message service (SMS) and internet. While such programs are innovative, they are not without challenges, and it is not yet clear that they will substitute for existing agricultural extension systems. Many of these projects are recent. It is thus necessary to provide empirical evidence on how these projects are faring in regard to adoption of the mobile phone, which is the foundation for their use.

Thus, the major interest of this study is to assess whether mobile phones have been embraced in the agri-food sector in Sub-Saharan Africa, taking Ugandan dairy farmers as a case study. In case the mobile phone has been adopted, has it helped farmers in the agri-food sector by keeping them informed of what is happening in the markets? Are farmers well informed about the current market prices for their produce? Are farmers well connected to markets? These are some of the questions this paper endeavours to address.

\subsection{Technology Acceptance Model (TAM)}


A review of previous studies formed the basis on which hypotheses for this study were formulated. This study examines one prevalent theory, technology acceptance model (TAM), for investigating individual mobile phone acceptance in the context of agri-food markets in Africa.

A lot of literature has focused on factors that determine mobile phone acceptance and utilisation (Mathieson et al., 2001, Luarn and Lin, 2005). Different models have been proposed. TAM, adapted from the Theory of Reasoned Action (TRA), is one of the most widely accepted models in studying technology acceptance and use (Pai and Huang, 2011). One reason for TAM's popularity is perhaps its wealth of recent empirical support.

The TAM postulates that adoption of a new technology is determined by a user's behavioural intention to use the technology (Chuttur, 2009, Wu and Wang, 2005). Further, TAM puts forward two beliefs, perceived usefulness and perceived ease of use, for explaining variance in user's behavioural intentions. Perceived usefulness implies a belief that a person's use of a given technology will improve his or her job performance. On the other hand, perceived ease of use is the extent to which a person believes that using a given technology will be free of effort. From these beliefs, perceived ease of use is a predictor of perceived usefulness.

Researchers on technology adoption and information technology have done a lot of work on the TAM and concluded that it is valid in predicting an individual's acceptance of a technology. The TAM's constructs, nevertheless, according to some researchers, do not fully reflect the specific influences of technological and usage-context factors that may alter the user's acceptance (Luarn and Lin, 2005, Malhotra and Galletta, 1999). It is important that future research on technology use and acceptance addresses how other variables affect usefulness, ease of use and acceptance (Chuttur, 2009). It is also equally important to investigate what can motivate a user to adopt or use a technology. The TAM's main constructs, perceived ease of use and perceived usefulness perhaps may not fully explain user's behavioural intention towards the use of mobile phones. This has motivated a search for other factors which can forecast acceptance of mobile phones, especially in the agri-food sector (Luarn and Lin, 2005). Researchers have extended the TAM and added constructs like trust, perceived playfulness, cognitive absorption, product involvement and perceived enjoyment. Luarn and Lin (2005) extended the model by adding perceived credibility in a mobile banking context. Prior to that, other researchers had introduced trust, perceived self-efficacy and perceived financial cost to the TAM in an online banking context. Since internet banking and mobile banking are technologies related to mobile phone use, this study extends the TAM by adding two measurement variables, perceived advantage and socio-economic characteristics, as a motivating factor for mobile phone technology in the agri-food sector (Mittal et al., 2010, Mittal and Tripathi, 2009, Tadesse and Bahiigwa, 2015). This study postulates that one of the advantages of mobile phones is that it keeps farmers updated on the current market prices for their products, i.e. they use it to find out prices of produce in different markets. The study also postulates that socio-economic characteristics of farmers also affect both perceived ease of use and perceived usefulness, which eventually affect mobile phone adoption.

\section{Research model and hypotheses}

The model for this study is presented in Figure 1. Like other studies which extend TAM, we eliminated the construct on "attitudes" (Mathieson et al., 2001, Chuttur, 2009). We aim to test the hypotheses in the Ugandan context. The hypotheses proposed are supported by literature on technology adoption. 


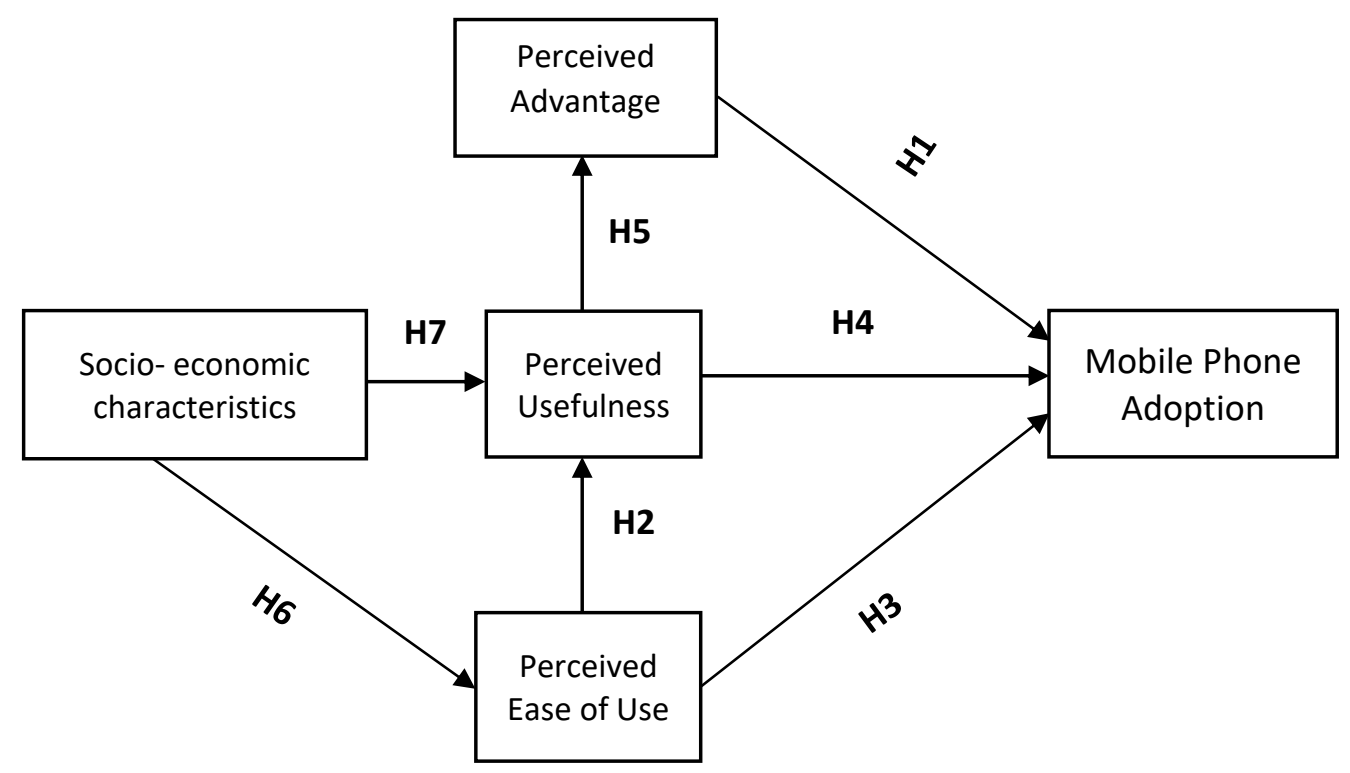

Figure 1: Model for the research

\subsection{Perceived advantage}

Perceived advantage is the extent to which a person believes that using a mobile phone will simplify some activities, especially for communication (Malhotra and Galletta, 1999, Luarn and Lin, 2005, Chuttur, 2009). During our fieldwork, several farmers confirmed that consideration of perceived advantage is likely to influence adoption of mobile phones. Some of the perceived advantages of mobile phones include normal communication with relatives and friends and gaining access to market prices for different market locations. With mobile phones, farmers are able to access information from different markets (Aker, 2009, Kim et al., 2008). Subsequently, perceived advantage is influenced by perceived ease of use and perceived usefulness (Park and del Pobil, 2013). Certainly, economic motivations and outcomes, such as advantages that come together with using a given technology, are a major focus for technology acceptance and adoption studies. The information above leads to the following hypothesis:

H1: Perceived advantage has a positive effect on mobile phone adoption.

\subsection{Perceived ease of use}

Previous research provides evidence on the effect perceived ease of use has on adoption of a technology, whether directly or indirectly affecting perceived usefulness (Wu and Wang, 2005, Luarn and Lin, 2005). A mobile phone must be easy to learn and use in order for users to embrace it (James, 2009b). This prevents the technology from being under-used. Perceived ease of use has been found to have a significant effect on both perceived usefulness and behavioural intention to use mobile banking and internet banking (Chuttur, 2009, Wu and Wang, 2005). Given this information, which is also useful for mobile phone adoption, we proposed the following hypotheses:

H2: Perceived ease of use has a positive effect on perceived usefulness of mobile phones.

H3: Perceived ease of use has a positive effect on mobile phone adoption. 


\subsection{Perceived usefulness}

Normally, people take up a technology if they find it useful. Extensive research in technology adoption provides evidence on the effect of perceived usefulness on mobile phone technology adoption (Nabhani et al., 2016, Luarn and Lin, 2005). Under this construct, we tested the following hypotheses:

H4: Perceived usefulness has a positive effect on mobile phone adoption.

H5: Perceived usefulness has a positive effect on perceived advantage of mobile phones.

\subsection{Socio- economic characteristics}

Previous research has evidence on the effect of socio-economic characteristics on technology adoption (Nabhani et al., 2016). Our study tests the effect of some socio-economic characteristics on perceived usefulness and perceived ease of use of mobile phones. Hence, we tested the following hypotheses:

H6: Socio-economic characteristics have a positive effect on perceived ease of use of mobile phones.

H7: Socio-economic characteristics have a positive effect on perceived usefulness of mobile phones.

\section{Research design and method}

\subsection{Measuring constructs}

We ensured content validity of the scales used in this study. We did this by making sure that the items selected represent the concept around which generalisations are to be made. As such, some of the items chosen as constructs were modified from earlier studies to ensure content validity. Instruments for perceived usefulness and perceived ease of use display good convergent, and also discriminant properties are reliable. Statements for perceived usefulness and perceived ease of use, with reference to previous studies, were modified to fit the current study. The items for the remaining constructs, socio- economic characteristics, perceived advantage, and mobile phone adoption were developed specifically for this study. Likert scales (1-5), ranging from "strongly agree" to "strongly disagree" were employed for most of the statements. Prior to data collection, pre-testing the measures was conducted through dairy farmers who own/access mobile phones. Where necessary, some items in the questionnaire were modified to make them fit for the study.

\subsection{Data collection}

Data for this study was collected from three Ugandan districts (Kabarole, Kiruhura and Kyegegwa). Uganda is a country located in East Africa. Respondents were dairy farmers with access to mobile phones. The questionnaire was administered by trained research assistants, using a mobile phone (with an application called Kobo Collect). The questionnaire consisted of items for all the constructs listed in Figure 1, with a request for demographic information. A total of 300 respondents were interviewed. Seventy-seven percent of the completed questionnaires were from male respondents. The respondents' age ranged from 18 to 94 years (mean $=49.19$ years). Thirty-five percent had completed primary education, twenty-five percent had secondary education. Only fifteen percent had no formal education. The remaining twenty-five percent had post-secondary education. The majority of the respondents (75\%) were married. 


\section{Data analysis and results}

\subsection{Measurement model}

Using Stata 13.1, a confirmatory factor analysis was conducted to test the measurement model. Several indices can be applied to evaluate model fit. However, no single index is sufficient for judging the quality of a model (Liu et al., 2010, Luarn and Lin, 2005, Park and del Pobil, 2013). We applied the model-fit measures shown in Table 1 to assess the model's overall goodness-of-fit: the ratio of $x^{2}$ to degrees-of-freedom, comparative fit index (CFI), Tucker-Lewis index, root mean squared error of approximation (RMSEA) and standardized root mean squared residual (SRMR). As Table 1 reveals, all the model-fit indices exceeded their respective common acceptance levels suggested in previous research. This proves that the measurement model exhibited a fairly good (acceptable) fit with the data collected. We then proceeded to evaluate the psychometric properties of the measurement model in terms of reliability and convergent reliability.

\section{Table 1. Statistics of model fit indices}

\begin{tabular}{lll}
\hline Model fit measure & Recommended value & Model measure \\
\hline $\mathrm{X}^{2} /$ d.f. & $<3.0$ & 1.6 \\
Root mean squared error of approximation (RMSEA) & $<0.08$ & 0.04 \\
Standardized root mean squared residual (SRMR) & $<0.09$ & 0.06 \\
Comparative fit index (CFI) & $>0.90$ & 0.91 \\
Tucker-Lewis index (TLI) or Non-normed fit index & $>0.90$ & 0.90 \\
PCLOSE & $>0.05$ & 0.91 \\
Critical N & $>200$ & 300 \\
\hline
\end{tabular}

Reliability and convergent validity of the factors were estimated by composite reliability (CR) and Cronbach's alpha (Table 2). The formula for computing composite reliabilities (Raykov, 1997) is shown below:

$$
C R=\frac{\left(\sum \lambda_{i}\right)^{2}}{\left(\sum \lambda_{i}\right)^{2}+\left(\sum \epsilon_{i}\right)}
$$

whereby, $\lambda$ is the standardized factor loading for item $i$ and $\varepsilon$ is the respective error variance for item $i$. The error variance $(\varepsilon)$ is estimated based on the value of the standardized loading $(\lambda)$ as:

$$
\epsilon_{i}=1-\lambda_{i}^{2}
$$

The item r-square value is the percent of the variance of item $i$, explained by the latent variable. It is estimated based on the value of the standardized loading $(\lambda)$ as: 


$$
r^{2}=\lambda_{i}^{2}=1-\epsilon_{i}
$$

The interpretation of the composite reliability coefficients, as shown in Table 2, is similar to that of Cronbach's alpha; the only difference is that it takes into account the actual factor loadings instead of assuming that each item is equally weighed in the composite load determination. The composite reliabilities for all the factors in the measurement model were above the recommended 0.7 level. Also, convergent validity can be evaluated by examining factor loadings from confirmatory factor analysis (Table 2). Factor loadings greater than 0.5 are considered to be very significant (Liu et al., 2010, Park and del Pobil, 2013). All the factor loadings of the items in our model were greater than 0.5. Besides, all the factors also had Cronbach's alpha above the recommended 0.6. Hence, all factors in the measurement model had adequate reliability and convergent validity.

\subsection{Structural model}

Table 1 shows the same set of indices which were used to examine the structural model. Comparing all the fit indices with their corresponding recommended values provides evidence of a good model fit. We then proceeded to examine the path coefficients of the structural model.

Figure 2 presents properties of the causal paths, standard coefficients and explanation of variance for each of the hypothesized equations in the model. Hypothesis $\mathrm{H} 3$ was as expected. On the other hand, hypotheses $\mathrm{H} 1$ and $\mathrm{H} 4$ were supported but not as expected. Altogether, perceived ease of use, perceived usefulness and perceived advantage accounted for $32 \%$ of the variance in mobile phone adoption, with perceived ease of use $(\beta=0.65)$ contributing more to mobile phone adoption than the contribution by perceived advantage and perceived usefulness ( $\beta=-0.20$ for each). Hypotheses $\mathrm{H} 2, \mathrm{H} 6$ and $\mathrm{H7}$ were supported, as expected. Perceived ease of use had a positive and significant effect on perceived usefulness $(\beta=0.33)$. Socio-economic characteristics was also found to have a positive and significant effect on both perceived ease of use $(\beta=0.23)$ and perceived usefulness $(\beta=0.18)$. Generally, only one hypothesis (H5) could not be supported by the data.

Table 2. Descriptive statistics of the constructs and items

\begin{tabular}{llllll}
\hline Variable & Mean & S.D & $\begin{array}{l}\text { Factor } \\
\text { loading }\end{array}$ & $\begin{array}{l}\text { Cronbach's } \\
\text { alpha }\end{array}$ & $\begin{array}{l}\text { Composite } \\
\text { reliability }\end{array}$ \\
\hline Perceived ease of use (PEOU) & & & & 0.70 & 0.76 \\
PEOU1 & 2.18 & 0.97 & 0.618 & & \\
PEOU2 & 1.83 & 1.16 & 0.701 & & \\
PEOU3 & 2.34 & 1.29 & 0.596 & & \\
PEOU4 & 2.65 & 1.24 & 0.521 & & \\
PEOU5 & 1.44 & 0.90 & 0.588 & & \\
PEOU6 & 2.42 & 1.37 & 0.508 & & \\
Perceived usefulness (PUS) & & & & 0.62 & \\
PUS1 & 2.54 & 1.28 & 0.620 & & \\
PUS2 & 1.55 & 0.99 & 0.604 & & \\
PUS3 & 1.40 & 0.84 & 0.672 & & \\
PUS4 & 1.87 & 1.14 & 0.585 & & \\
PUS5 & 2.08 & 0.92 & 0.598 & & \\
\hline
\end{tabular}




\begin{tabular}{llllll}
\hline Perceived advantage (PAD) & & & & 0.66 & 0.80 \\
PAD1 & 1.53 & 1.06 & 0.812 & & \\
PAD2 & 1.54 & 1.18 & 0.829 & & \\
PAD3 & 1.92 & 1.42 & 0.603 & & \\
Mobile phone use (MPU) & & & & 0.72 & 0.80 \\
MPU1 & 1.91 & 1.42 & 0.713 & & \\
MPU2 & 2.00 & 1.18 & 0.548 & & \\
MPU3 & 1.87 & 1.46 & 0.731 & & \\
MPU4 & 2.01 & 1.19 & 0.587 & & \\
MPU5 & 1.79 & 1.41 & 0.637 & & \\
MPU6 & 2.07 & 1.61 & 0.580 & & \\
Socio economic characteristics (SEC) & & & & 0.75 & \\
SEC1 & 49.19 & 17.31 & 0.868 & & \\
SEC2 & 32.95 & 18.11 & 0.830 & & \\
SEC3 & 1.74 & 0.44 & 0.715 & & \\
\hline
\end{tabular}

*Please refer to appendix 1 for the details of the constructs used in this table

In addition to the direct effects in Figure 2, the model also has indirect effects. The first indirect effect is from socio-economic characteristics through perceived usefulness, i.e. $0.18^{*}-0.2=-0.036$; the second is from socio-economic characteristics through perceived usefulness and perceived advantage, i.e. $0.18 *-0.043 *-0.2=0.002$; the third is from socio-economic characteristics through perceived ease of use, i.e. $0.23 * 0.65=0.15$; the fourth is from socio-economic characteristics through perceived ease of use and perceived usefulness, i.e. $0.23 * 0.33 *-0.2=-0.02$; the fifth is from socio-economic characteristics through perceived ease of use, perceived usefulness and perceived advantage, i.e. 0.23 $* 0.33 *-0.043 *-0.2=0.0007$; the sixth is from perceived ease of use through perceived usefulness, i.e. $0.33 *-0.2=-0.07$; and the seventh is from perceived ease of use through perceived usefulness and perceived advantage, i.e. $0.33 *-0.043 *-0.2=0.003$. Hence, the total effects (both direct and indirect) for all the constructs on mobile phone adoption is $0.28(=0.002+0.15+0.65+0.0007+0.003$ $-0.036-0.02-0.07-0.2-0.2)$. 


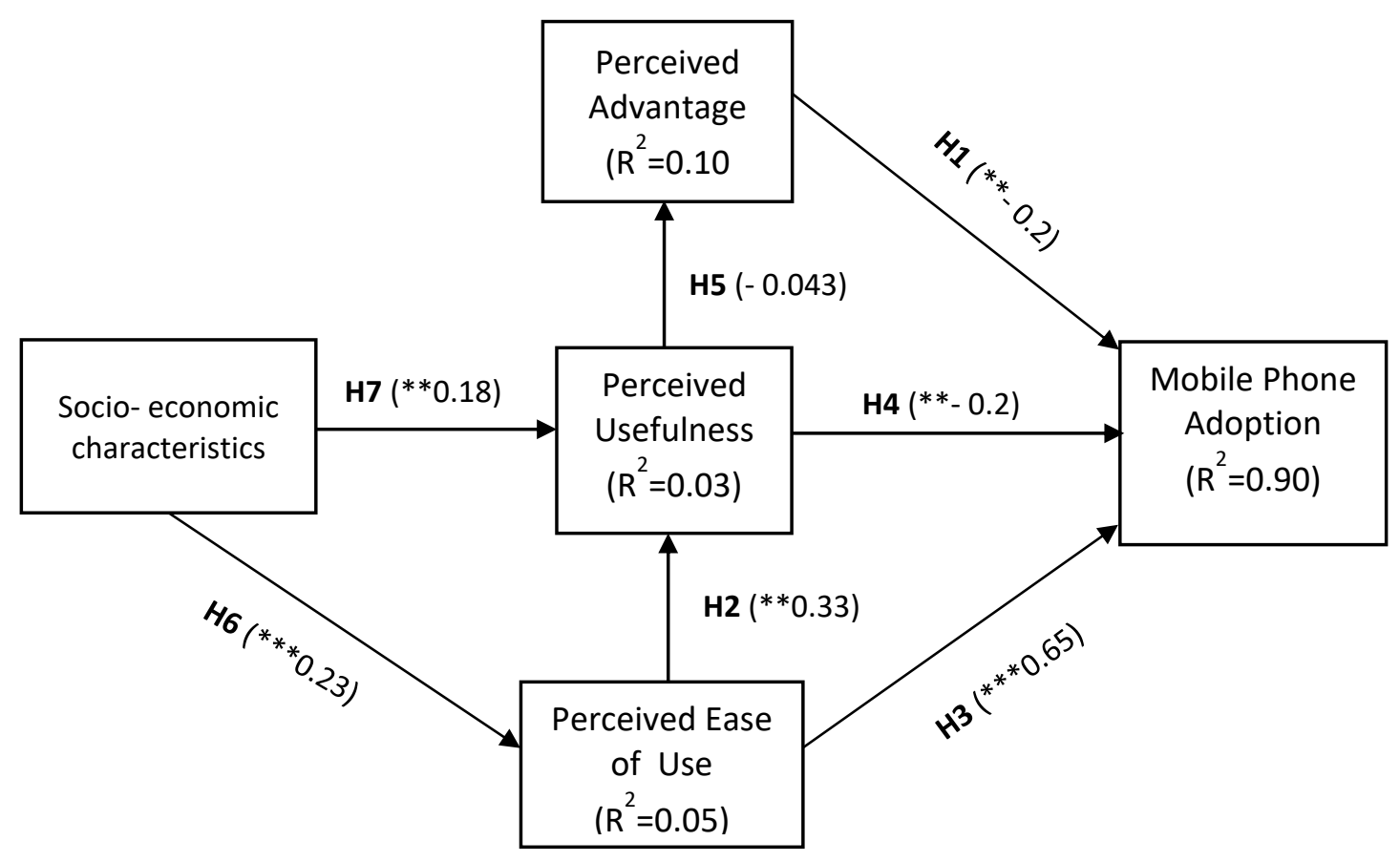

Note: $* * \mathrm{P}<0.05 ; * * * \mathrm{P}<0.001$

Figure 2: Results for the test model.

\section{Discussion}

The role of technology acceptance model (TAM) is to inform implementers of a technology whether or not individuals who the technology is targeting will accept and adopt it. For mobile phone adoption in Sub-Saharan Africa, the results from this model gives insights on what mobile phone companies, extension workers, government and other stakeholders need to do in order for this technology to benefit the farming community in the region. Research reveals that it is farmers in the agricultural value chains who are not yet utilising the mobile phone maximally. Other chain actors (e.g. traders, middlemen, processors, transporters) are benefiting much from the technology.

Perceived usefulness and perceived ease of use are the key constructs of the TAM. For this particular study, we added two more constructs, perceived advantage and socio-economic characteristics. Perceived ease of use has a significant and positive effect on both perceived usefulness and adoption of mobile phones. This effect is stronger than other variables in the model. Perceived ease of use was also found to have a significant effect on both perceived usefulness and behavioural intention to use adopt mobile banking and internet banking (Chuttur, 2009, Wu and Wang, 2005). For any technology to be easily adopted, it must be easy to use. The fact that mobile phones are easy to use accounts for their popularity in the recent past (GSM, 2015, GSMA, 2016). Most dairy farmers in the study area (Uganda) at least have access to mobile phones. The perception that mobile phones are easy to use is very important for all stakeholders in the mobile phone industry. For the mobile phone companies, they can introduce more applications useful to the farming communities. For non-governmental and developmental organisations working to improve the welfare of farmers in Sub-Saharan Africa, this perception can help them design (together with mobile phone companies) applications relevant to the farming communities. Such applications can be for monitoring weather and prices for both inputs and produce. Some of these applications have already been rolled out in a few countries like Bangladesh (Goggin and Clark, 2009), India (Abraham, 2006), Niger (Aker and Ksoll, 2016), and Ethiopia (Tadesse and Bahiigwa, 2015). 
Unlike previous studies on the application of TAM, perceived usefulness and perceived advantage in this study did not positively influence adoption of mobile phones. To some extent, this was anticipated since this study assessed how farmers use mobile phones in exchanging information on milk prices in different markets. With reference to this, dairy farmers did not find perceived usefulness and perceived advantage as a motivation to using mobile phones. Most of the respondents disagreed with the statements on mobile phone use in relation to exchange of milk price information. The majority of farmers in the agri-food sector who own mobile phones use them mainly for normal communication, i.e. keeping in touch with relatives and family and not as a means of exchanging information on prices of produce or commodities (Wyche and Steinfield, 2015). The mobile phones, according to these farmers, are mainly for making phone calls, sending SMS and sending/receiving money (mobile money app) to/from friends and family. Apparently, mobile money service has gained a lot of popularity in Sub-Saharan Africa (GSM, 2015). The service is used for making and receiving payments. Even in farming communities, this service is very popular. This is because of its massive publicity.

In Sub-Saharan Africa, it is very paramount that extension workers and the relevant institutions that promote marketing of agricultural produce promote mobile phones as a medium of searching and exchanging market information. In order for farming communities to view mobile phones as a means of acquiring and exchanging market information, mobile phone companies (e.g. Vodafone, Airtel, MTN Orange) should design more applications and increase publicity of the current ones through trainings, seminars, conferences, workshops, public awareness campaigns, and social activities (e.g. marathons). These activities will change the perception of farmers towards usefulness, ease of use and advantages of mobile phones. This will consequently increase mobile phone adoption directly or indirectly (Figure 2). The overall objective of the above campaign is for farmers to use mobile phones for accessing information on inputs, prices for their produce, weather, etc. (Shimamoto et al., 2015, Aker and Ksoll, 2016, Aker and Mbiti, 2010).

Results in Figure 2 further reveal that perceived ease of use of mobile phones has a significant effect on perceived usefulness of the technology. The perception on the ease of use of any technology apparently affects its perceived usefulness. This argument also holds for mobile phone adoption (Tadesse and Bahiigwa, 2015). The only challenge is that the indirect influence of perceived ease of use of mobile phone adoption was not significant; the explanation for this is the previous paragraphs.

Socio-economic characteristics, the only external variable in the model, influenced significantly both perceived usefulness and perceived ease of use. We included this variable because research has shown that technology adoption is influenced by age, household size and the time a farmer has spent in farming (Fisher et al., 2015, Croppenstedt et al., 2003, Fisher and Snapp, 2014, Ndiritu et al., 2014, Khonje et al., 2015). As Figure 2 shows, socio-economic characteristics influenced significantly perceived ease of use, which subsequently influenced mobile phone use. This argument finds supported in previous research (Gurtner et al., 2014, Nikou and Mezei, 2013, Wang and Sun, 2016). As Gurtner et al. (2014) puts it, age is very important in mobile phone adoption. Whereas age is very important for adults in terms of usefulness and ease of use of a technology, it is less important for the young generation. Our findings, like previous studies, suggest that socio-economic characteristics should be put into consideration when promoting adoption of any technology, more especially in SubSaharan Africa (Conci et al., 2009). Interestingly, farming is the back-borne of most economies in SubSaharan Africa. However, the youth, who form a big percentage of the population in this region, are not very much into farming (Labonne and Chase, 2009, Bhavnani et al., 2008, Abraham, 2006). With the popularity of the smartphone technology, the youths can be convinced to embrace farming. In order for this to happen, mobile telephone companies can design more applications that incorporate 
farming into social media. As they go on with social media, the youth can come into contact with farming communities elsewhere, nationally and internationally. Goggin and Clark (2009) report results of a study where mobile phones (Grameenphone) helped in engaging communities in different activities of community development. Such activities included agriculture, markets, and HIV/healthcare.

Although some variables did not significantly affect mobile phone adoption positively, the overall effect, i.e. both direct and indirect paths, was 0.28 . This was further supported by R-square of $90 \%$, which was quite good compared to some previous studies (Park and del Pobil, 2013, Liu et al., 2010). This model, therefore, represents a good improvement in explanatory power and is very useful in explaining mobile phone adoption in Sub-Saharan Africa.

\section{Conclusions}

We have presented results of a study which added two constructs, perceived advantage and socioeconomic characteristics to technology acceptance model (TAM). Consequently, we used the extended TAM to assess adoption of mobile phones in the farming communities in Sub-Saharan Africa. The study population was 300 dairy farmers from Uganda. This section summarises the findings of this study and presents theoretical and practical contributions of the paper. Limitations of the study are also highlighted and areas for further research are pointed out in this section.

This paper contributes to limited literature on mobile phone adoption in agri-food sector of SubSaharan Africa by providing empirical evidence from Ugandan farmers. This was achieved by adding two constructs, perceived advantage and socio-economic characteristics to the technology acceptance model. Our research also contributes to promoting mobile phone use in farming communities beyond just normal communication. This will subsequently improve the investment opportunities and doing business in the region. The following paragraphs throw more light on this practical contribution of our research.

Evidence from this paper shows that perceived ease of use is a major antecedent to mobile phone adoption; this is in consistent with previous studies. On the other hand, perceived advantage and perceived usefulness influence mobile phone adoption negatively. To some extent, this was anticipated since the majority of the farmers who participated in the study use mobile phones mainly for normal communication and not for marketing their produce by searching for and exchanging information on prices. This therefore calls for awareness campaigns by relevant stakeholders in order to change the mind-set of these farmers towards mobile phone use. The awareness campaigns can be spearheaded by telecommunication companies but guided by developmental and non-governmental organisations working for the welfare of farmers. In the long run both telecommunication companies and farmers will be the sole beneficiaries. The telecommunication companies will increase their business opportunities and hence revenue. For the farmers, their produce will be competitive. The mobile phones will create a business mind-set in them; they will be well informed about markets and they will take their produce to customers with the best price on offer. Thus, the study has strong practical implications for farmers as well as other stakeholders from the agri-food sector.

This study has also shown that socio-economic characteristics have a positive and significant impact on both perceived usefulness and perceived ease of use of mobile phones. This variable does not have any direct influence on mobile phone adoption. It only has indirect effects through perceived ease of use, perceived usefulness and perceived advantage. 
Despite its success, this study had a number of limitations which need to be pointed out. The data was collected from Ugandan dairy farmers with access to mobile phones. There is need for more research in order to generalize these findings and discussion to include other technologies and/or user groups. Extending this study beyond Uganda and particularly in Sub-Saharan countries would be also interesting. In addition, there is need to include more variables which can improve the ability to more accurately predict technology adoption. Furthermore, our model was cross-sectional, i.e. it measured perceptions at a single point in time. Apparently, perceptions change over time as individuals gain experience. For anyone interested in predicting mobile phone adoption over time, this change has implications. Thus, more effort to evaluate validity of these findings and the model is required. Longitudinal evidence would help predict behaviour and beliefs over time. Future studies can also explore the challenges of mobile phone adoption across Sub-Saharan region.

\section{Appendix 1: Constructs Used in this Study}

\section{Perceived ease of use (PEOU)}

PEOU1. A mobile phone satisfies most of my agriculture information needs.

PEOU2. I use my mobile phone for all my business transactions.

PEOU3. I directly contact universities for information on new pesticides and animal drugs.

PEOU4. A mobile phone helps me acquire instant weather information.

PEOU5. A mobile phone has enabled me interact well with clients and fellow farmers

PEOU6. A mobile phone helps me secure loans.

\section{Perceived usefulness (PUS)}

PUS1. A mobile phone has become a new way of marketing milk.

PUS2. I talk to agriculture or veterinary officials at the district when I need any information on my cattle.

PUS3. I inquire about animal diseases and available remedies in the market from farmers using my mobile phone.

PUS4. The phone has reduced transport costs since I do not search for clients physically.

PUS5. I am more informed on milk prices by owning a mobile phone.

\section{Perceived advantage (PAD)}

PAD1. A mobile phone has enabled me make timely decisions.

PAD2. A mobile phone has enabled me provide timely services.

PAD3. A mobile phone has promoted market transparency.

\section{Mobile phone use (MPU)}

MPU1. I am able to negotiate better prices for my livestock on mobile phone.

MPU2. I usually sell my milk to clients whom I contact over the phone. 
MPU3. With my phone I am able to get current market prices for milk.

MPU4. With my phone I sell milk in the market myself.

MPU5. A mobile phone helps me access information on market prices for milk.

MPU6. A mobile phone has enabled me secure better prices.

\section{Socio economic characteristics (SEC)}

SEC1. I am years old.

SEC2. I have spent years in farming or rearing animals.

SEC3. I am the household head of the family.

\section{References}

ABRAHAM, R. Mobile phones and economic development: Evidence from the fishing industry in India. Information and Communication Technologies and Development, 2006. ICTD'06. International Conference on, 2006. IEEE, 48-56.

AKER, J. 2009. Information from markets near and far: Information technology, search costs and grain markets. Mimeo, Tufts University.

AKER, J. C. 2010. Dial "A" for agriculture: using information and communication technologies for agricultural extension in developing countries. Tuft University, Economics Department and Fletcher School, Medford MA02155, 37.

AKER, J. C. \& FAFCHAMPS, M. 2015. Mobile phone coverage and producer markets: Evidence from West Africa. The World Bank Economic Review, 29, 262-292.

AKER, J. C. \& KSOLL, C. 2016. Can mobile phones improve agricultural outcomes? Evidence from a randomized experiment in Niger. Food Policy, 60, 44-51.

AKER, J. C. \& MBITI, I. M. 2010. Mobile phones and economic development in Africa. The Journal of Economic Perspectives, 24, 207-232.

ALBIMAN, M. M., ALBIMAN, M. M., SULONG, Z. \& SULONG, Z. 2016. The role of ICT use to the economic growth in Sub Saharan African region (SSA). Journal of Science and Technology Policy Management, 7, 306-329.

AMANKWAH-AMOAH, J. 2016. Global business and emerging economies: Towards a new perspective on the effects of e-waste. Technological Forecasting and Social Change, 105, 20-26.

AMANKWAH-AMOAH, J. 2015. Solar Energy in Sub-Saharan Africa: The Challenges and Opportunities of Technological Leapfrogging. Thunderbird International Business Review, 57, 15-31.

ASONGU, S. A. \& LE ROUX, S. 2016. Enhancing ICT for Inclusive Human Development in Sub-Saharan Africa.

ASONGU, S. A. \& NWACHUKWU, J. C. 2016. The Mobile Phone in the Diffusion of Knowledge for Institutional Quality in Sub-Saharan Africa. World Development, 86, 133-147.

BATCHELOR, S., SCOTT, N., VALVERDE, A., MANFRE, C. \& EDWARDS, D. 2014. Is there a role for Mobiles to support Sustainable Agriculture in Africa? 2nd International Conference on ICT for Sustainability (ICT4S 2014), 272-280.

BAYARD, B. \& JOLLY, C. 2007. Environmental behavior structure and socio-economic conditions of hillside farmers: a multiple-group structural equation modeling approach. Ecological Economics, 62, 433-440.

BHAVNANI, A., CHIU, R. W.-W., JANAKIRAM, S., SILARSZKY, P. \& BHATIA, D. 2008. The role of mobile phones in sustainable rural poverty reduction. retrieved November, 22, 2008.

CHAVULA, H. K. 2014. The role of ICTs in agricultural production in Africa. Journal of Development and Agricultural Economics, 6, 279-289. 
CHUTTUR, M. Y. 2009. Overview of the technology acceptance model: Origins, developments and future directions. Working Papers on Information Systems, 9, 9-37.

CONCI, M., PIANESI, F. \& ZANCANARO, M. 2009. Useful, social and enjoyable: Mobile phone adoption by older people. Human-computer interaction-INTERACT 2009, 63-76.

COSTANTINI, V. \& LIBERATI, P. 2014. Technology transfer, institutions and development. Technological Forecasting and Social Change, 88, 26-48.

CROPPENSTEDT, A., DEMEKE, M. \& MESCHI, M. M. 2003. Technology adoption in the presence of constraints: the case of fertilizer demand in Ethiopia. Review of Development Economics, 7, 58-70.

DEICHMANN, U., GOYAL, A. \& MISHRA, D. 2016. Will digital technologies transform agriculture in developing countries? Agricultural Economics, 47, 21-33.

DOSS, C. R. 2006. Analyzing technology adoption using microstudies: limitations, challenges, and opportunities for improvement. Agricultural Economics, 34, 207-219.

FAIDA, M. 2006. Chain empowerment: supporting African farmers to develop markets.

FAO 2003. WTO Agreement on Agriculture: The Implementation Experience - Developing Country Case Studies. In: THOMAS, H. (ed.) Commodities and Trade Division. Rome: Food and Agriculture Organization of the United Nations (FAO).

FEDER, G., JUST, R. E. \& ZILBERMAN, D. 1985. Adoption of agricultural innovations in developing countries: A survey. Economic development and cultural change, 33, 255-298.

FISHER, M., ABATE, T., LUNDUKA, R. W., ASNAKE, W., ALEMAYEHU, Y. \& MADULU, R. B. 2015. Drought tolerant maize for farmer adaptation to drought in sub-Saharan Africa: Determinants of adoption in eastern and southern Africa. Climatic Change, 133, 283-299.

FISHER, M. \& SNAPP, S. 2014. SMALLHOLDER FARMERS'PERCEPTIONS OF DROUGHT RISK AND ADOPTION OF MODERN MAIZE IN SOUTHERN MALAWI. Experimental Agriculture, 50, $533-$ 548.

FUCHS, C. \& HORAK, E. 2008. Africa and the digital divide. Telematics and informatics, 25, 99-116.

GALANG, R. M. N. 2012. Government efficiency and international technology adoption: The spread of electronic ticketing among airlines. Journal of International Business Studies, 43, 631-654.

GOGGIN, G. \& CLARK, J. 2009. Mobile phones and community development: a contact zone between media and citizenship. Development in Practice, 19, 585-597.

GSM 2015. The mobile economy Sub-Saharan Africa 2015. GSMA Intelligence. Regional report https://gsmaintelligence. com/research.

GSMA 2016. The Mobile Economy 2016.

GURTNER, S., REINHARDT, R. \& SOYEZ, K. 2014. Designing mobile business applications for different age groups. Technological Forecasting and Social Change, 88, 177-188.

JAIN, L., KUMAR, H. \& SINGLA, R. 2015. Assessing mobile technology usage for knowledge dissemination among farmers in Punjab. Information Technology for Development, 21, 668676.

JAMES, J. 2009a. From the relative to the absolute digital divide in developing countries. Technological Forecasting and Social Change, 76, 1124-1129.

JAMES, J. 2009b. Leapfrogging in mobile telephony: A measure for comparing country performance. Technological Forecasting and Social Change, 76, 991-998.

JAMES, J. \& VERSTEEG, M. 2007. Mobile phones in Africa: how much do we really know? Social indicators research, 84, 117.

KASSIE, M., JALETA, M., SHIFERAW, B., MMBANDO, F. \& MEKURIA, M. 2013. Adoption of interrelated sustainable agricultural practices in smallholder systems: Evidence from rural Tanzania. Technological forecasting and social change, 80, 525-540.

KASSIE, M., TEKLEWOLD, H., JALETA, M., MARENYA, P. \& ERENSTEIN, O. 2015. Understanding the adoption of a portfolio of sustainable intensification practices in eastern and southern Africa. Land Use Policy, 42, 400-411.

KATZ, J. E. 2008. Handbook of mobile communication studies, The MIT Press. 
KHONJE, M., MANDA, J., ALENE, A. D. \& KASSIE, M. 2015. Analysis of adoption and impacts of improved maize varieties in eastern Zambia. World Development, 66, 695-706.

KIBERE, F. N. 2016. The Paradox of Mobility in the Kenyan ICT Ecosystem: An Ethnographic Case of How the Youth in Kibera Slum Use and Appropriate the Mobile Phone and the Mobile Internet. Information Technology for Development, 22, 47-67.

KIM, D. Y., PARK, J. \& MORRISON, A. M. 2008. A model of traveller acceptance of mobile technology. International Journal of Tourism Research, 10, 393-407.

LABONNE, J. \& CHASE, R. S. 2009. The power of information: the impact of mobile phones on farmers' welfare in the Philippines.

LIU, I.-F., CHEN, M. C., SUN, Y. S., WIBLE, D. \& KUO, C.-H. 2010. Extending the TAM model to explore the factors that affect Intention to Use an Online Learning Community. Computers \& education, 54, 600-610.

LUARN, P. \& LIN, H.-H. 2005. Toward an understanding of the behavioral intention to use mobile banking. Computers in human behavior, 21, 873-891.

MALHOTRA, Y. \& GALLETTA, D. F. Extending the technology acceptance model to account for social influence: Theoretical bases and empirical validation. Systems sciences, 1999. HICSS-32. Proceedings of the 32nd annual Hawaii international conference on, 1999. IEEE, $14 \mathrm{pp}$.

MARTIN, B. \& ABBOTT, E. 2010. Development calling: the use of mobile phones in agriculture development in Uganda. International Federation for Information Processing (IFIP), Technical Commission.

MATHIESON, K., PEACOCK, E. \& CHIN, W. W. 2001. Extending the technology acceptance model: the influence of perceived user resources. ACM SigMIS Database, 32, 86-112.

MITTAL, S., GANDHI, S. \& TRIPATHI, G. 2010. Socio-economic impact of mobile phones on Indian agriculture, Indian Council for Research on International Economic Relations New Delhi.

MITTAL, S. \& TRIPATHI, G. 2009. Role of Mobile Phone Technology in Improving Small Farm Productivity1. Agricultural Economics Research Review, 22, 451-459.

MUTO, M. \& YAMANO, T. 2009. The impact of mobile phone coverage expansion on market participation: Panel data evidence from Uganda. World development, 37, 1887-1896.

NABHANI, I., DARYANTO, A. \& RIFIN, A. 2016. Mobile Broadband for the Farmers: A Case Study of Technology Adoption by Cocoa Farmers in Southern East Java, Indonesia. AGRIS on-line Papers in Economics and Informatics, 8, 111.

NDIRITU, S. W., KASSIE, M. \& SHIFERAW, B. 2014. Are there systematic gender differences in the adoption of sustainable agricultural intensification practices? Evidence from Kenya. Food Policy, 49, 117-127.

NIKOU, S. \& MEZEI, J. 2013. Evaluation of mobile services and substantial adoption factors with Analytic Hierarchy Process (AHP). Telecommunications Policy, 37, 915-929.

OSABUTEY, E. L. \& JIN, Z. 2016. Factors influencing technology and knowledge transfer: configurational recipes for Sub-Saharan Africa. Journal of Business Research.

OUMA, S. A., ODONGO, T. M. \& WERE, M. 2017. Mobile financial services and financial inclusion: Is it a boon for savings mobilization? Review of Development Finance.

OVERÅ, R. 2006. Networks, distance, and trust: Telecommunications development and changing trading practices in Ghana. World Development, 34, 1301-1315.

PAI, F.-Y. \& HUANG, K.-I. 2011. Applying the technology acceptance model to the introduction of healthcare information systems. Technological Forecasting and Social Change, 78, 650-660.

PARK, E. \& DEL POBIL, A. P. 2013. Technology acceptance model for the use of tablet PCs. Wireless personal communications, 73, 1561-1572.

RAYKOV, T. 1997. Estimation of composite reliability for congeneric measures. Applied Psychological Measurement, 21, 173-184.

ROUSE, M. 2014. Definition of digital divide.

SEKABIRA, H. \& QAIM, M. 2017. Can mobile phones improve gender equality and nutrion? Panel data evidence from farm households in Uganda. GlobalFood Discussion Papers. 
SHIMAMOTO, D., YAMADA, H. \& GUMMERT, M. 2015. Mobile phones and market information: Evidence from rural Cambodia. Food Policy, 57, 135-141.

TADESSE, G. \& BAHIIGWA, G. 2015. Mobile phones and farmers' marketing decisions in Ethiopia. World Development, 68, 296-307.

UBOS 2016. 2016 Statistical Abstract. http://www.ubos.org/publications/statistical-abstract/.

WANG, Q. \& SUN, X. 2016. Investigating gameplay intention of the elderly using an Extended Technology Acceptance Model (ETAM). Technological Forecasting and Social Change, 107, 59-68.

WU, J.-H. \& WANG, S.-C. 2005. What drives mobile commerce?: An empirical evaluation of the revised technology acceptance model. Information \& management, 42, 719-729.

WYCHE, S. \& STEINFIELD, C. 2015. Why Don't Farmers Use Cell Phones to Access Market Prices? Technology Affordances and Barriers to Market Information Services Adoption in Rural Kenya. Information Technology for Development, 1-14. 